\title{
Would You Rather: A Focus Group Method for Eliciting and Discussing Formative Design Insights with Children
}

\author{
Lucy Simko \\ Paul G. Allen of Computer Science \& \\ Engineering, University of \\ Washington \\ USA \\ Harkiran Kaur Saluja \\ Information School, University of \\ Washington \\ USA \\ Alexis Hiniker \\ Information School, University of \\ Washington \\ USA
}

\author{
Britnie Chin \\ Human Centered Design \& \\ Engineering, University of \\ Washington \\ USA
}

Tian Qi Zhu

Human Centered Design \&

Engineering, University of

Washington

USA

Jason Yip

Information School, University of

Washington

USA

\author{
Sungmin $\mathrm{Na}$ \\ Department of Sociology, University \\ of Washington \\ USA
}

Tadayoshi Kohno

Paul G. Allen of Computer Science \& Engineering, University of

Washington

USA

Camille Cobb

CyLab, Carnegie Mellon University

USA

\begin{abstract}
Would you rather go 1000 days without the Internet or five days where anyone can read your mind? We present "Would You Rather" (WYR), a technique for generating formative design insights (inspired by the conversational game of the same name) that combines design provocations with forced-choice scaffolding. Here, we describe the components of a WYR session, which include scenario generation, voting, and group discussion. As children disproportionately benefit from scaffolding during the co-design process, we also report on an evaluation of the technique with 16 children, conducted across seven sessions and spanning the course of one year. We find that WYR fulfills recommendations for focus groups (e.g. eliciting mental models and values, producing focused yet animated discussion) and leverages playfulness, humor, structure, and forced choice to overcome known common challenges of designing with children.
\end{abstract}

ACM Reference Format:

Lucy Simko, Britnie Chin, Sungmin Na, Harkiran Kaur Saluja, Tian Qi Zhu, Tadayoshi Kohno, Alexis Hiniker, Jason Yip, and Camille Cobb. 2021. Would You Rather: A Focus Group Method for Eliciting and Discussing Formative Design Insights with Children. In Interaction Design and Children (IDC '21), June 24-30, 2021, Athens, Greece. ACM, New York, NY, USA, 16 pages. https://doi.org/10.1145/3459990.3460708

\section{INTRODUCTION}

Designers are most likely to create technologies that respect children's values and best meet their needs when they involve children

This work is licensed under a Creative Commons

Attribution-NonCommercial-ShareAlike International 4.0 License.

IDC '21, fune 24-30, 2021, Athens, Greece

(C) 2021 Copyright held by the owner/author(s)

ACM ISBN 978-1-4503-8452-0/21/06.

https://doi.org/10.1145/3459990.3460708 in the design process $[19,20]$. To elicit children's perspectives, ideas, and opinions, researchers often draw upon user-centered design methodologies such as focus groups, interviews, co-design, and participatory design. However, many of these traditional approaches are more challenging to execute with children than with adult participants. For instance, children's developing executive function can result in focus group sessions where children need to move about physically or spend less time focusing on a single task [27]. Children may find it more difficult to express abstract thoughts [58], or require additional support to overcome power differentials with adult researchers. Creating design methods that account for these needs can lead to more productive design partnerships with children.

In this paper, we introduce Would You Rather (WYR), a co-design technique [60] for scaffolding focus groups to surface design insights related to technology tradeoffs, dilemmas, tensions, and risks. WYR is based on a conversational game of the same name played in social settings, often by children and teens [65]. In the original game, players take turns posing thought-provoking scenarios that force the other players to choose between two options. The scenario always begins with the preamble "Would you rather," as in, "Would you rather have only pie or have only cake?" The game is more conversational than competitive, but the "best" scenarios for design are typically those that result in a split vote or cause players to struggle to choose. Often, both choices are undesirable, resulting in a provocation wherein the player must choose the lesser of two evils: for example, "Would you rather fight 100 duck-sized horses, or a single horse-sized duck?" Illustrating the pervasiveness of this game in popular culture, there are many apps, games, and online quizzes designed around this concept (e.g., [24, 37, 46]).

The WYR co-design technique entails children voting for WYR scenarios, discussing their votes, creating their own WYR questions, and using WYR as a way to design low fidelity prototypes. We conducted several pilot sessions to refine our methodology, and present, 
in this paper, our findings from seven design sessions with elementary and middle school children ages 6-11 in an intergenerational co-design group. Our research questions are:

(1) Engagement: How do kids engage with WYR? What kinds of behaviors might future practitioners encounter?

(2) Output: What can we learn through the WYR method? What kinds of insights might future researchers derive?

In this paper, we first turn to related work and background about co-design with children in Section 2. In Section 3, we describe the key stages of the WYR methodology as a guide for future practitioners. In Section 4, we introduce our design study of seven sessions with a group of 16 children (ages 7-11). Then, in Section 5, we address our research questions with the results of our design study, finding, for example, that (1) WYR keeps participants engaged and incites animated conversation, and (2) WYR helps children reason about tradeoffs and complex decisions and express their preferences and abstract values through forced choice and fantasy. Finally, in Section 6, we conclude with a discussion of how WYR relates to other prior approaches and reflect on the mechanisms that make WYR successful.

We contribute to the IDC community in three ways. Methodologically, we comprehensively outline different ways WYR can be implemented. Empirically, we demonstrate through our design sessions how children responded to WYR. Theoretically, we show how WYR incorporates children's development of intersubjectivity $[62,64,74]$ as a way to elicit and understand their perspectives.

\section{BACKGROUND AND RELATED WORK}

\subsection{The importance of involving children in the design process}

Children are important stakeholders when designing technology for them and their families, and they are also frequent technology owners and users themselves [49]. Therefore, designers must consider children's needs-yet doing so can require different methods than for adults [20]. Studies with children leverage a variety of methodological techniques, using different ways to overcome the challenges of working with kids. One broad category of techniques to involve children in the design process is participatory design [20,48], which attempts to bring users and designers together on common footing and equal ground [4, 8, 23, 70].

A number of studies in the IDC community have demonstrated that children and adults can work together in democratic collaboration on the design of new technologies [18, 25, 36, 52, 69, 72]. Researchers and designers often involve children directly in the design process as users, testers, informants, and design partners [20], as children are the experts on their own experience.

\subsection{Traditional co-design methodologies can be difficult for children}

Since children are still developing executive function [30, 41, 47], respondent strategies like interviews, focus groups, and surveys are not always effective for children [27]. For instance, interviews offer a deep connection with adult participants, yet may not allow the same connection with a child participant due to the power dynamic between the adult researcher and the child [63]. Additionally, children, who may make up memories, are often unreliable witnesses $[10,50]$. A survey offers a structured choice and allows data collection from many participants, but is difficult with children due to developing language and literacy skills [12].

A focus group involves a group of approximately eight participants discussing a topic set by a researcher, who moderates or directs the conversation [44, 45]. A successful focus group has a non-intimidating environment $[5,26,44,55]$, animated discussion or debate [5, 26], focused discussion and moderation [5, 45], and it elicits participants' mental models, values, and attitudes [5, 26, 44, 55]. However, conducting traditional focus groups with children presents challenges because executive function skills (including attentional control and cognitive flexibility) are still developing in children. Until being "relatively mature" [1] at age 12 [9, 47, 73], children may require different research techniques than adults, and many of the challenges of focus groups with adults are amplified when working with children. Prior work has found that PD methods can be more engaging and productive with children than traditional surveys, interviews, or focus groups [19, 20, 41]. We argue that new techniques for elicitation of perspectives of children need to focus on the following three characteristics:

Attention span. Traditional interviews, surveys, and focus groups are difficult for children due shortened attention spans [1, 38, 73]. Underdeveloped executive function impedes their ability to control their attention, self-regulate, self-monitor, and self-inhibit [1], which, in traditional focus groups, surveys, and interviews, may lead children to lose interest in the topic, switch conversation topics, physically wander away, or strike up side conversations.

Abstract and complex thinking. Children are simultaneously developing the ability to think abstractly and complexly [ 1 , 47,73 ], "a prerequisite to meaningful verbal expression" [9]. In elicitation techniques, the goal is often to understand participants' values and beliefs by asking probing questions like "why?" [5, 26, $44,45,55]$, but due to developing executive function and language skills development, children may give tautological, inconsistent, or surface-level answers to such questions $[9,38]$.

Group dynamics. In addition to factors caused by developing executive function, research groups with children run into similar problems as with adults with regards to group dynamics: power dynamics among children can prevent seamless collaboration when some are domineering and some are quiet, or can lead to off-topic sessions and excessive silliness that hinders design output and idea generation [56, 57]. However, we know from child development that group activities are important for children and their skills development [59].

\subsection{Developing new techniques for elicitation for children}

In HCI and IDC, there is a practice of creating new co-design with children that leverage imagination, structure, and play to overcome both the researcher-child power dynamic and children's difficulties with abstract thinking and self-reflection. Scaffolding is a metaphor that educators use to describe the role of how guides, simplified tasks, reminders, and socialization can support children shift from dependence to greater independence as children acquire skills and knowledge for themselves [33, 59, 66]. In IDC, researchers often use 
design techniques with builtin scaffolds as a way to provide support, mediate, and strategize how to keep design tasks simple, breaking design into smaller tasks, and reminding children of the goals of the task. For instance, Guha et al. scaffold brainstorming and group cooperation through discrete stages in which children first generate ideas individually, then come together in small groups to "mix ideas," and then the entire class shares ideas [29]. Comicboarding allows children who are not accustomed to ideation to draw out design scenarios by filling in comic panels with characters, plot formats, and interactions [43]. Other techniques scaffold children to explain their experiences, context, preferences, and opinions to a researcher through the use of fantasy, overcoming the inherent power dynamic between adult researchers and children. In "Mission from Mars," child participants explain something about their world to a "Martian," who can ask questions that a "normal" human researcher might not [16]. Through Fictional Inquiry, Dindler and Iversen allow children to "bypass existing socio-cultural structure" and engage in PD with adult research partners by setting a fantasy land in which children play themselves [17].

Walsh et al. offer a structured methodology for creating techniques [61] to consider how to scaffold design techniques for children. We highlight the following dimensions in our consideration of an elicitation technique for children's ideas in co-design.

- Partner experience: WYR does not require children to have design experience.

- Need for accommodation: Adults may have to help children express their abstract ideas.

- Design space: WYR's design space tends to be non-specific and focused on understanding children's larger contexts.

- Maturity of design: WYR focuses on early stage designs to foster more ideas.

- Cost: WYR requires no high cost materials for the activity other than a mechanism for capturing discussion data.

- Portability: Due to requiring no specialized materials and being flexible in terms of materials, WYR is highly portable and can travel from place-to-place wherever children are.

- Technology: As related to cost, the amount of technology needed is minimal.

- Physical interaction: As elicitation focuses on dialogue, WYR requires lower physical movement.

\section{HOW TO USE WYR}

Here we describe how to use the WYR method, including preparing, running, and analyzing data from a design session. The key stages of WYR are: scenario generation, voting and discussion, and analysis. In Section 3.4, we describe how the development of WYR across seven pilot sessions led to this process.

\subsection{Stage 1: Scenario generation}

The "best" WYR scenarios present a difficult decision, aiming (1) to split the vote between two choices, and (2) to create choices that are not obvious for the participants. These characteristics will help engage participants in discussion and debate, in which they explain and justify their choices. We found it was most natural to create negative scenarios where both hypothetical choices were unpleasant; however, it is also possible to create a choice between with positive scenarios (which we did in our sixth session, as summarized in Table 1).

Scenarios may be created by researchers before the session begins (Option 1a), or by participants during the session (Option 1b). We describe our recommendations for both below. For both, we found it helpful to equip researchers with ideas for structuring WYR scenarios. For example, one possible structure is Always or Never, as in "WYR always have a video playing on your TV or never get to watch videos again?" To this end, we include a set of template structures derived from our pilot sessions and popular media such as BuzzFeed quizzes [46] in Appendix B.

3.1.1 Option 1a: Researchers create scenarios (pre session). For some WYR sessions, researchers create the scenarios before the sessions. Researchers should do what works best for their group and creative process, but we emphasize that creating WYR is just that: a creative process best done in groups with an open minded attitude where no idea is a bad idea. We recommend creating more scenarios than will be needed for the session and prioritizing the best ones. We found that seven to ten scenarios was appropriate for our 1-hour sessions, but this number might vary. Researchers might also find value in our advice for guiding participants' scenario generation (Option 1b).

3.1.2 Option 1b: Participants create scenarios (in session). Participantgenerated scenarios-including the process of generating scenarioscan be another mechanism for research insight, but are not necessary for successful sessions. We recommend conducting scenario generation only when most participants are already familiar with WYR. This could be at the end of a longer session (i.e., after voting on and discussing several pre-existing scenarios) or across multiple sessions with the same participants. Researchers should participate in or moderate participants' scenario generation process and treat this as an additional source of study data.

Researchers can help participants create engaging scenarios by preparing scaffolding, such as partially-filled scenarios (e.g., "WYR only be able to watch one good video per day or __?" or "WYR have unlimited horrible videos or __ good videos per day?”). In one pilot session, we used an "idea box" from which participants could pick suggestions to spark their imagination. Working in groups can help participants and researchers can build off each other's ideas, though researchers should be cognizant that children may need to feel ownership over their part of the idea [29].

\subsection{Stage 2: Voting and discussion}

The vote-discuss cycle comprises the core of the WYR method: for each scenario, participants (1) vote on what they would prefer, and (2) discuss their choice, moderated or at least observed by a researcher. We recommend WYR sessions start with a brief votediscuss cycle about a simple scenario, such as "Would you rather have candy for breakfast or pancakes for dessert?" to introduce the game. Researchers may then explain their focus topic before introducing scenarios pertinent to their research questions.

3.2.1 Stage 2a: Voting. Asking participants to choose between two scenarios-voting-is how WYR seeds insightful discussion. The exact voting mechanism is flexible but could have the following characteristics. First, each vote should be visible to researchers 


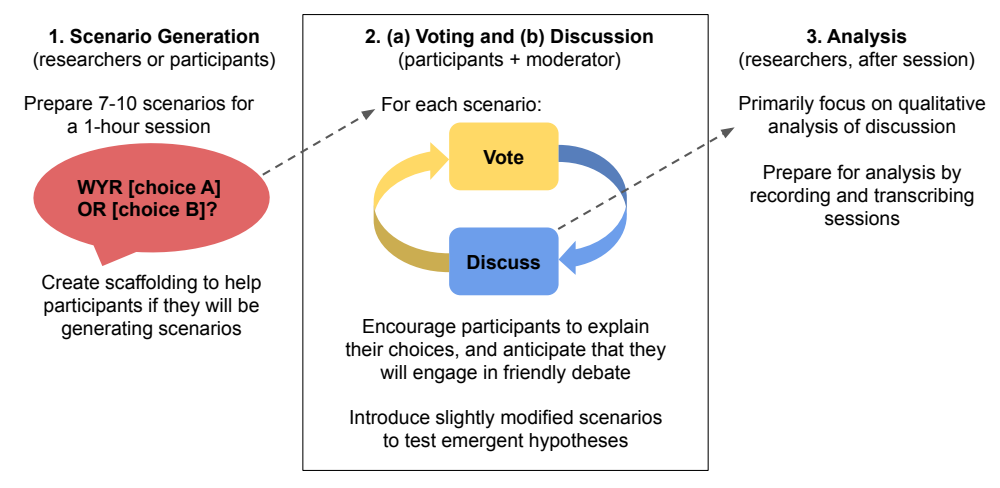

Figure 1: WYR requires initial scenario generation, but sessions predominantly consist of voting and discussion. Data analysis should focus on discussion over votes.

and other participants. Next, the outcome of the vote should be clear at a glance. Participants should also be able to opt out to indicate indecision or a rejection of both options. Researchers may participate in the vote to show collaboration. In some sessions, participants placed stickers on a wall to vote, but most sessions used line judging, in which participants stand along a spectrum to indicate their choice; standing in the middle indicates that they cannot decide [61]. Our online sessions used an adaptation of line judging where participants indicated their choice by holding their hand near the top or bottom of their face, or near their nose to indicate indecision.

3.2.2 Stage 2b: Discussion. Voting invokes discussion that may spontaneously elicit mental models, values, concerns, and personal context through debate between participants or explanations of the voting. The discussion time, which is tied to each voting period, offers a way to test emergent hypotheses through follow-up questions. For example, researchers can ask about variant scenarios to probe the factors that contribute to participants' choices. Having dedicated discussion time also allows researchers to invite contributions from quieter voices and keep the group on topic.

For a fruitful discussion stage, we recommend discussing each scenario right after voting on it. During discussion, we encourage researchers to ask participants about the votes, e.g., why they voted a certain way or why others might have chosen differently. Researchers also might discuss how alternate scenarios would change votes. Both researchers and participants may pose follow-up informal scenarios based on emergent hypotheses. Finally, we suggest that if participants change their mind (and their vote) during discussion, to allow them to express their thoughts.

\subsection{Stage 3: Analysis}

Practitioners can use qualitative analysis methods (e.g., recording and transcribing sessions, open or inductive coding to identify themes, and seeking consensus about themes within the research team); as an example, our qualitative analysis process is described in Section 4.2. Analyzing vote counts quantitatively should be approached with caution, as quantitative vote outcomes may be complicated by the ways that participants' choices are influenced by group dynamics [56]-either to intentionally be contrary or to vote with their friends or the majority of other participants.

\subsection{Developing WYR through pilot sessions}

We developed the WYR methodology through seven pilot sessions, during which we maintained an iterative process journal, summarized in Appendix A. Our goal in these pilot sessions was to understand, practically, how to conduct WYR as a co-design methodology. Pilot sessions took place in a variety of contexts (e.g., classrooms, open houses, social hours) and included participants from a variety of age ranges and backgrounds (e.g., adults, middle and high school children and their parents, graduate students, undergraduate students). From our pilot sessions, we learned:

- Scope. WYR sessions should focus on a specific topic without being overly restrictive (e.g., the first several pilot sessions, generally about computer security and privacy, produced interesting discussions but did not predictably elicit specific design insights).

- Participants. WYR was adaptable to groups of varying sizes, worked with children, teens, and adults, and was engaging even when participation was fleeting (e.g., at open houses).

- Voting and discussion mechanisms. WYR's unstructured vote-discuss periods-i.e., with larger and transient groups at open houses in which participants came and left over a period of hours-elicited discussion that was hard to capture. When participants saw others' votes paired with demographic information (e.g., age), they asked questions like "Why would an adult choose that?"

- Capturing data. In order to capture discussions, researchers should consider audio or video recording, potentially using multiple cameras and/or microphones with different breakout groups. In our pilot sessions, we saw enthusiastic participation in large groups and transitory settings, but capturing discussion data in these sessions was difficult.

\section{METHODS}

To evaluate and further refine the WYR method after our pilot sessions, we conducted seven additional WYR sessions with children through participatory design methods (PD) and following the WYR method as specified in Section 3. Table 1 presents an overview of 


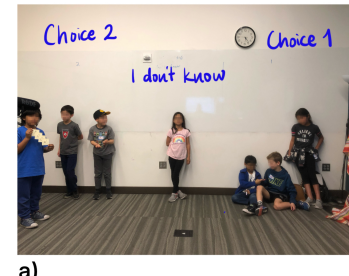

a)

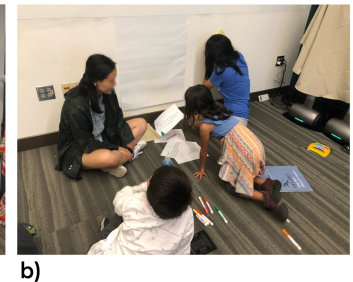

b)

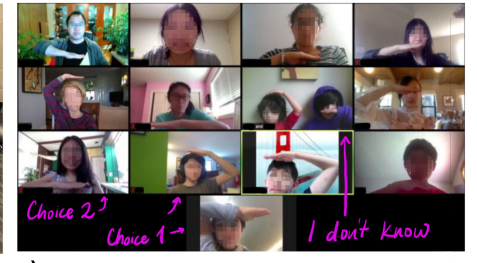

c)

Figure 2: (a) Using line judging to vote in WYR; (b) Collaborating with adults to generate new WYR scenarios; (c) Modified line judging used in a virtual WYR session.

\begin{tabular}{|c|c|}
\hline Session Overview & Example Scenario \\
\hline $\begin{array}{l}\text { WYR1 Focus on "Creepy Tech," based on prior work [71]. Scenarios chosen } \\
\text { in advance by researchers. }\end{array}$ & $\begin{array}{l}\text { WYR play with a cute robot that secretly changes your Wi-Fi password or } \\
\text { a scary robot that does not secretly change anything? }\end{array}$ \\
\hline $\begin{array}{l}\text { WYR2 Focus on "Creepy Tech" [71]. Scenarios generated by participants } \\
\text { with researcher guidance, starting with one example. }\end{array}$ & $\begin{array}{l}\text { WYR have a creepy robot that acts like your parent and watches you during } \\
\text { the night or a robot with a creepy smile that randomly plays scary clown } \\
\text { music? }\end{array}$ \\
\hline $\begin{array}{l}\text { WYR3 Scenarios chosen in advance by researchers based on those from } \\
\text { pilot sessions, which focused on computer security and privacy. }\end{array}$ & $\begin{array}{l}\text { WYR have your parents know everything you did at school through video } \\
\text { cameras or your teacher know everything you did at home through video } \\
\text { cameras? }\end{array}$ \\
\hline WYR4 Focus on school. Scenarios chosen in advance by researchers. & $\begin{array}{l}\text { WYR your teacher knows exactly how long you spent on homework or } \\
\text { you have } 5 \text { hours of homework every day and the teacher has no idea how } \\
\text { long you're spending? }\end{array}$ \\
\hline $\begin{array}{l}\text { WYR5 Focus on YouTube. Scenarios generated and chosen by participants } \\
\text { with researcher guidance and instructions to tweak one of several pre- } \\
\text { generated example scenarios. }\end{array}$ & WYR have unlimited horrible videos or one good video per day? \\
\hline $\begin{array}{l}\text { WYR6 Positive scenarios (i.e., scenarios with a choice between two desir- } \\
\text { able options), chosen in advance by researchers. Conducted via Zoom due } \\
\text { to Covid-19. }\end{array}$ & WYR never have to go back to school or never have to go back on Zoom? \\
\hline $\begin{array}{l}\text { WYR7 Focus on the game slitherio. Scenarios generated and chosen by } \\
\text { participants with researcher guidance. Participants told to play the game } \\
\text { before session to inform brainstorming. Conducted via Zoom due to Covid- } \\
19 \text {. }\end{array}$ & $\begin{array}{l}\text { WYR have infinite zoom so you don't poop out little worm bits and get } \\
\text { smaller when you zoom or grow by two times the normal amount when } \\
\text { you eat things? }\end{array}$ \\
\hline
\end{tabular}

Table 1: Overview of the topic, methodological variations, and an example scenario from each of our WYR design sessions.

these sessions, WYR1-7, and Figure 2 includes images from the sessions. PD is a method of design that brings users and designers together to democratically collaborate with each other $[19,22]$. Although WYR is appropriate for people of varied ages, we chose to evaluate the method by working with children (ages 6-11), because common challenges of focus groups are especially pronounced with children [56]. If WYR can help overcome common challenges found in children, it may be promising for other contexts and participants as well.

Second, children in the longer term intergenerational co-design group were already knowledgeable about multiple co-design techniques. These two reasons let us try different variations of WYR. Finally, PD techniques have allowed children to more concretely express abstract ideas [21, 29, 30, 60, 67]. In particular, Cooperative Inquiry partnerships with children have been shown to produce indepth conversations and rich data around sociotechnical issues like intelligent user interfaces, cybersecurity, online safety and privacy, and creepiness in technology [71].

\subsection{Participants}

An intergenerational co-design group, consisting of both adult design researchers (university investigators and doctoral, masters, and undergraduate students) and child participants ( $\mathrm{n}=16$; ages 6-11) participated in seven design sessions from April 2019 to June 2020. The team is called KidsTeam UW (children's names are pseudonyms, Table 2). At the time of the study, all children had 1-5 years of experience in KidsTeam UW. Our PD sessions focused on trying WYR: eliciting children's perceptions, constructing their own WYR questions, and designing based on WYR responses. In each of the WYR sessions, approximately seven adults facilitators supported the children as design partners.

\subsection{Data Collection and Analysis}

We recorded WYR1-5 using a video camera and microphone setup. For WYR3-5, a facilitator moved the camera throughout the design sessions to focus on specific group interactions and different conversations. We also recorded the online WYR6 and 7 sessions, which mostly included facial expressions and audio. We approached data analysis using grounded, inductive, and qualitative methods [11]. Our coding process mirrors many HCI studies that focus less on the codes as the product, and emphasize the codes as a process [40].

We do not treat the coding results as data, but rather as structures that helped guide our inquiry and interpretations so that we may depict our interpretation of the complexity of the data [32]. 


\begin{tabular}{lllll|llllc}
\hline Name & Age & Gender & Ethnicity & Sessions & Name & Age & Gender & Ethnicity & Sessions \\
\hline Ash & 11 & Boy & Hispanic & $1-7$ & Ian & 9 & Boy & White & $3,4,6,7$ \\
Ben & 7 & Boy & Hispanic & $4-7$ & Jade & 6 & Girl & Asian-White & $2,4,5,7$ \\
Carol & 10 & Girl & Asian-White & 6,7 & Kat & 6 & Girl & Asian-White & 3 \\
Dwight & 8 & Boy & Asian-White & $2-7$ & Lynn & 7 & Girl & Asian-White & Asian \\
Emma & 11 & Girl & Asian-White & $5-7$ & Mike & 11 & Boy & White & 1,2 \\
Fiona & 7 & Girl & Asian-White & 1 & Norm & 10 & Boy & Asian-White \\
George & 6 & Boy & Hispanic-White & 3 & Ophelia & 9 & Girl & Asian & 4,5 \\
Henry & 9 & Boy & Asian-White & $2,3,5-7$ & Pat & 9 & Girl & Native American-Asian & 1,2 \\
\hline
\end{tabular}

Table 2: Demographic information for each (pseudonymous) participant and which sessions they participated in.

We began with an inductive analysis of a total of 450 minutes of video. Four co-authors watched the videos and created an initial set of analytic memos of their observations. After the analytic memos were completed, the four co-authors then transcribed the entire WYR1-7 video set. For WYR1 and 2, we focused our transcription efforts on the larger group discussion. During WYR3-5, because the camera moved throughout the design session, we transcribed the conversations and the larger group discussion. For online WYR6 and 7, we also transcribed the larger group discussions.

Once we finished transcriptions, we began open-coding the data by compiling an initial list of codes. These codes, based on our analytic memos and first watch-throughs, began with the loopholes children created, the kinds of questions they asked back to the adults, the dilemmas they encountered, the kinds of questions that generate split votes, and the kinds of WYR scenarios they created. We then iteratively organized the first set of codes over the course of seven group discussions. As the codes began to surface, we began to merge and identify common themes.

In our second round revisions of the codebook, we refined our codebook into the following categories (Appendix E): 1) Situations that might be unreal, pragmatic/realistic, or both; 2) Debates amongst the children; 3) Uniform vs. split votes; 4) Children asking for more clarification; 5) Contextual information about the children's lives; 6) Coping strategies children take to mitigate the WYR situation; 7) Mental models about how technology works; 8) Children's values; 9) How children recognize power dynamics; and 10) Recognizing tensions and conflicts in a WYR situation.

Four coders then applied the refined codes. Each coder acted as both primary and secondary coder. The primary coder first coded the transcripts, and then the secondary coder verified the codes and identified additional coded data. Then, we had six group meetings where we discussed and did a comparative analysis of each code to note similarities and differences. Coding disagreements were mediated by a third coder. As we applied the coding scheme, we also further refined the codebook, adding subthemes. In a collaborative axial coding session [14], we then compared and contrasted our final coding to analyze emergent themes; our results coalesce these codes into higher-level takeaways. We aimed to include terminology that closely matches the codebook, but sometimes deviate, e.g., discussing power dynamics separately in terms of children's mental models of other people and as a contextual detail of who other stakeholders are in their lives. We also discuss some codes together, e.g., clarifying questions and finding loopholes.

\section{DESIGN STUDY FINDINGS}

We now describe the findings of our WYR design sessions. We first outline typical behaviors that children engaged in during the sessions (RQ1), which can help researchers create a productive atmosphere, even when this might mean-counterintuitively-going along with seemingly subversive behaviors. Then, we characterize the content of sessions into several types of insights that emerged repeatedly across sessions (RQ2).

\subsection{How children engage with WYR}

Children in our design sessions were actively engaged with WYR. They quickly grasped the premise, gave thoughtful responses, and paid attention to each other, leading to constructive discussions with design insights (see Section 5.2). When the same group of children participated in multiple WYR sessions, they remembered the earlier session (e.g., Henry recalled at the start of WYR3 that "some of the questions were super hard"). Remarkably, their engagement with the activity carried over to sessions conducted via Zoom due to COVID-19 (WYR6 and WYR7), despite the added complexity of not being together in person (e.g., cross-talk with friends being harder) and the children needing to be more physically still so that they could stay on camera. Children's engagement was characterized by creativity (e.g., suggesting unexpected ways to avoid harmful hypothetical outcomes), and humor (e.g., incorporating pooping, farting, or inside jokes in their scenarios, like a choice in WYR4 about being forced to listen to the "bagel song" they had been singing before the session started).

5.1.1 Debate prompts children to verbalize arguments supporting their choices. Children engaged in lively, friendly debates about our WYR scenarios, which prompted them to explain their reasoning. For example, arguing that a phone that "secretly watches you" was preferable to one that "prevents you from having fun," Dwight explained that he was okay with being watched because "it never said it would tell anybody." Jade was unconvinced by this argument: "But it'll watch you in the bathroom," which prompted Henry to push back: "That's only if you bring it into the bathroom."

As demonstrated, children often defended their choices, and they frequently did so by constructing sound arguments that referred to elements of the scenarios. Although children often make locally flawed or incomplete arguments and have trouble expressing abstract reasoning or principles [2], we observed them using coherent grounds, warrants, and qualifiers to support their claim that a given choice was preferable, roughly following Toulmin's 
structure of valid arguments [54]. Interactions with other children helped them address holes in their arguments. Animated debate like this has also been emphasized as a key component of successful focus groups $[5,26]$.

5.1.2 Confronting Ambiguity Generates Design Insights. Children regularly sought clarifying details about the scenarios. In WYR1, Fiona asked if the "tricks" a hypothetical robot would play on her were "like [a] whoopee cushion?" Conversely, sometimes children directly took advantage of these ambiguities by bringing up a loophole that would make their choice objectively and obviously better.

When children identify loopholes or ask for clarifying details, these interactions can give researchers insights about what influences their decisions. Using this updated knowledge, researchers can construct emergent hypotheses and craft modified scenarios to probe further. In WYR1 we presented a scenario in which the children could "play with a cute robot that constantly sends information to [their] parents, or ... a scary robot that [only] sends some information." Ash chose the cute robot, because "my parents don't really check their emails." Pat and Norm agreed, since they know their parents are already overwhelmed by the volume of email they receive. This eventually led to a modified scenario in which information went through a middleman, prompting several children to change their minds and leading to a conversation about trustworthy versus creepy middlemen.

These behaviors help children explore the bounds of the scenario; researchers' reactions may help shape their understanding of it. Encouraging children to seek out and discuss loopholes can lead to productive insights.

5.1.3 Non-votes can convey useful insights. Our use of line judging gave children an explicit option to reject both scenario choices.The relative infrequency with which children used this option, even when both scenario options were undesirable, demonstrates their understanding of and engagement with the activity (e.g., in WYR1, 43 of the 50 total votes cast were for one of the scenario options). When they did refuse to make a choice, children sometimes tautologically told us that they could not choose because they were not sure. Other times, their explanation conveyed insight about the tensions the choice posed. For example, in WYR1, Fiona could not choose between "an Alexa device that records everything you say, or ... [one that] pretends it's your parent." She enthusiastically affirmed others' arguments against both choices; when asked why she could not choose, she countered with a question of her own: "why do people create technologies so creepily? It must be made by a drunk man.” By allowing Fiona to explain her indecision rather than forcing her into a choice, we learned that she could not envision logical and reasonable designers making creepy technologies, even though the security researchers on our team agreed that the first option was not unrealistic.

5.1.4 Participants' emphasis on specificity and detail provides an alternative mechanism for insight. After engaging with researchergenerated WYR scenarios several times, children came up with their own scenarios in WYR2, WYR5, and WYR7. For example, Ash and Henry were adamant about specific elements of a scenario they came up with in WYR5. Their scenario centered around another KidsTeam UW participant (Ian) and the controversial YouTube personality PewDiePie. After suggesting the scenario in a smaller breakout group, the lead researcher tried to introduce this scenario in a more generic way: "WYR watch your favorite YouTuber or your best friend on YouTube." Henry and Ash resisted: "Noo - it's would you rather watch PewDiePie or Ian on YouTube?" Their specificity, however, helped us learn about Henry and Ash's experience with YouTube and their knowledge about YouTube controversies, which could help inform research questions related to parental controls and problematic content on the platform.

Children's insistence on such details may demonstrate their difficulty expressing which aspects of the scenario are important to them without concrete details. Alternately, they may have been intentionally specific to prevent others from taking advantage of loopholes. As previously discussed, loopholes and ambiguity can be productive to discussion, so child-generated scenarios may be less useful in that respect. Researchers should anticipate that the scenarios children generate themselves will offer a different mechanism for research insights than researcher-generated scenarios.

5.1.5 Subversive engagement can be productive. We observed other behaviors that initially seemed subversive, but which were actually beneficial. For example, we observed children copying or manipulating each others' votes (i.e., moving the stickers used as votes) and parroting each others' explanations (e.g., Jade agreeing "same here with Lynn and me"). Previous work suggests that children are susceptible groupthink [56]. However, voting scaffolds discussion even if participants' votes do not represent their true desire. During the vote-discuss cycle, researchers should be aware of groupthink and, for example, change the order in which they invite explanations from friends who voted together.

Sometimes the discussion became disconnected from the original scenario. In WYR3, we asked "would you rather play with a robot that gives you food and water when you need it or a robot that cuddles you at night?" Dwight suggested "I would just ask it for candy because it said food and water." Even though the original scenario was about food and water, subsequent discussion focused on candy. Jade mixed up which choice included the "at night" clause, adding: "At night if you ask for candy you already brushed your teeth so you can't have it." Despite this explanation not being well-aligned with the original scenario, we learn about Jade's household rules and her mental model of technology-that such technology would not let her circumvent household rules and, therefore, would not be useful.

Breaking (perceived) rules can be fun, which helps keep children engaged with the activity. Additionally, breaking rules or being subversive can help them explore the bounds of the activity, enabling opportunities for more creative responses. Researchers will need to evaluate whether a seemingly off-topic or subversive form of engagement is too distracting, but should not immediately stifle unexpected behaviors.

\subsection{What researchers and designers learn through WYR}

Here, we summarize types of insights that can be derived from WYR sessions. These include contextual details about participants' lives; their mental models of technology, themselves, and others; and their values. 
5.2.1 Participants verbalize contextual details: resources, habits, routines, and experiences. Children brought up contextual details about their own situated experiences that they saw as relevant to the scenario. Understanding this context is critical to designing technology for children and families. For example, understanding children's view on parental limitations on technology might encourage a game designer to create more natural stopping points, so that children would not lose substantial progress in the game when they encounter parent-imposed limits on their play.

Children painted a picture of their access to various devices, such as phones and gaming devices. For instance, in WYR1, we learned that Fiona used her phone only to call her parents, not for games, so she was undeterred by scenario choices restricting phone use, because she is already "only allowed to use my smartphone one hour a day." Many of the other children had access to phones-even their own phones-yet their access was restricted.

In WYR3, from a scenario about a robot that either "gives you food and water when you need it or a robot that cuddles you all night," we learned about participants' possessions (e.g., stuffed animals that they imagined would be better for cuddling than a robot) and their bedtime routines (e.g., not eating after brushing their teeth). We also learned about other actors in their lives, such as their parents, teachers, and siblings, and the extent to which they trusted or distrusted them. Although many of these contextual details were not directly related to technology, their role in WYR scenarios can help designers interrogate ways that technology could better fit into users' lives.

5.2.2 Arguments for a WYR choice reveal mental models and participants' sense of agency over technology. Children's explanations taught us how they understand the world: how they believe technology or larger-scale systems work, their understanding of other people's behaviors, and their beliefs about their own abilities. Their explanations of security and privacy risks had nuance and their technical mental models seemed relatively accurate, given prior work on users' mental models of technology [39]. For example, in scenarios where technology collected data about them, the children elucidated concerns related to who could access the information, if the data collection happened consensually, and what someone might use their data for. They recognized that companies might sell their data, which they saw as troubling. WYR1 presented a choice in which the phone would "secretly [try] to get you buy stuff," but Norm observed that this already happens. Envisioning an even more malicious version of this choice, which closely approximates a real-world risk of "clickjacking" [34, 35], Fiona and Pat speculated that "[the ad] can pop up on your screen in the middle of, when you're like doing a-" (Fiona) "- and then what if it happens you accidentally press yes?” (Pat).

However, their mental models of technology were often flawed, and their proposed mitigation strategies implied they felt they had substantial control over technology. For example, in WYR4, Dwight and Ash suggested a scenario in which their teacher could watch them do homework, envisioning that the teacher would be "sitting in front of the computer screen, and they can monitor what is happening." Although Ash knew in WYR1 that his parents "don't really check their emails," his ideas about his teacher's motivation to surveil students outside of class were less realistic. Children also tended to overestimate their ability to mitigate risks. For example, even though Norm knew that companies may covertly advertise, he noted that "it secretly gets you to buy stuff, but you don't have to," perhaps underestimating his susceptibility to persuasive advertising.

5.2.3 Choices and hesitations convey participants' preferences and values. WYR scenarios are typically silly, absurd, and unrealistic, leading participants to disengage from the constraints of reality (which can support more effective design [16]), and paradoxically allowing them to explain how their choices were motivated by their values and preferences. In our sessions, we learned about preferences, desires for interpersonal relationships, and abstract views on morality and societal ideals. Children also discussed competing values that made some decisions especially difficult.

We repeatedly learned about the importance of specific technologies in participants' lives. Fiona said "I hate technology. Except iPads, iPhones and video games" and that going without WiFi would be "like going back to being a caveman." Mike declared "WiFi is my life," and Ian said "I cannot live without technology...I would die. I would go out and punch people." Others argued that other things are more important than internet access, such as Ash noting that "the only thing you need to live is just water and food," and Dwight recommending that instead of digital entertainment "you can just play a board game." In WYR6-held online at the beginning of our pandemic lockdown-we asked: "WYR never go back to school or never go back to Zoom?" Carol was unable to choose because this scenario forced her to weigh her values of friendship (difficult to maintain without Zoom) and "get[ting] a solid education."

WYR scenarios also provided participants with language to describe their abstract values as well as the heirarchy of those values. For example, in WYR2, Norm chose a nice robot with bloody sharp teeth over a cute robot that lies: "Because it's nice, like you want to be with someone who is nice, who cares if it is bloody?" The concreteness-and absurdity-of the scenario helped Norm explain that he valued honesty and kindness over aesthetics.

\section{DISCUSSION}

Successful group dialogue requires intersubjectivity, the development of shared meaning and understanding of an activity among group members [62, 64, 74]. Children often achieve intersubjectivity through social play and games. Piaget argues that children develop intersubjectivity through collective and standardized play symbols and that children can co-construct symbols together (e.g., draw pictures, create mental models) [47]. Vygotsky claims that the social rules that children jointly develop in play guide the activity through frequent negotiations [59]. Due to the nature of children's social and cognitive development, they have different needs than adults. As a result, interviewing, surveying, or using focus groups set up for adults may not allow children and researchers to develop the intersubjectivity needed to share ideas. In contrast, social play in WYR aligns with children's need for collaborative interaction and cultivating intersubjectivity. Through our deployments of WYR, we identified four key properties that we observed contribute to its utility as a co-design technique for children: (1) scaffolding; (2) fantasy; (3) group work; and (4) forced choice. 
Scaffolding. Like many social games that promote intersubjectivity, WYR embeds substantial scaffolding into its implementation. Other design methods have demonstrated the usefulness of providing this kind of structure; for example, comicboarding scaffolds the brainstorming process by providing participants with a partially complete comic strip [43]. Similarly, DesignLibs builds on the creativity of MadLibs games by presenting fill-in-the-blank or question-and-answer structured design scenarios to encourage participants to generate more creative, diverse, or feasible design ideas [7]. These approaches align with children's developmental needs, as scaffolding that is appropriate for a child's zone of proximal development can be very effective in supporting children's sociocultural development [59]. WYR provides scaffolding through its structured questions and clear delineations between votes. While interviews, surveys, and focus groups emphasize eliciting ideas from children, WYR can support how children develop their own understanding of complex situations. Throughout our sessions, we informally and formally modeled the creation of WYR questions to the children, and in turn had children create their own questions (WYR2), scenarios (WYR4-6), and designs (WYR7). Rather than asking complex ethical questions directly, we used the scaffolding of WYR to help children negotiate and become more independent in evaluating complex and nuanced scenarios.

Fantasy. A second key property of WYR is that it encourages participants to think beyond the constraints of reality. Because children have trouble expressing abstract and complex thoughts, play and fantasy help children "directly or symbolically act out feelings, thoughts, and experiences that they are not able to meaningfully express through words" [9]. Some existing PD techniques for children successfully employ fantasy, e.g. [16, 17], to elicit children's mental models, values, and contextual details of their lives. Other design methodologies-not specifically for children-focus on future thinking, that is, asking participants to specifically "rehearse the future" [31], or speculative design $[3,13]$ to help participants explore new ideas. Additionally, focus group experts have suggested that the use of humor in prompts can help both stimulate discussion and provide insight into participants' mental models [5, 38, 45] Barbour suggests the use of cartoons "since they often tap into and express succinctly in an amusing way, difficult and keenly felt dilemmas, but take the sting out of thinking about these. They thus, simultaneously, break the ice and give permission to raise difficult issues" [5]. The comical absurdity of the dilemmas in WYR frees participants to consider a choice that they would not need to make in practice, but encourages them to ground their reasoning in reality. It is through the use of fantastical play that children begin to construct and make known their abstract symbols (e.g., scenarios, questions, ideas) and their negotiations with the participants (e.g., justifications, loopholes, tensions, etc.).

Group activity. A third key property of WYR is that it is a group activity. Children use group dialogues to construct knowledge and understanding [59]. Children's interactions with other people, particularly those that may be more advanced (e.g., adult design partners), help mediate their encounters with the world through sensemaking, argumentation, and negotiation [42]. WYR builds on existing group methods by offering a provocative yet simple dialogue game that engages children and moderates discussion, overcoming common focus group challenges stemming from pacing or over- or under-eager participants [5, 38]. WYR's scaffolding keeps groups focused and allows moderators to seek clarification while still encouraging animated discussion and debate. The segmentation during the vote-discuss period allows moderators to naturally transition away from an off-topic conversation by beginning another vote or to seek clarification by asking a participant about their reasoning. It also allows moderators to engage both dominant and hesitant participants through non-verbal cues (as voting may occur verbally, non-verbally, or both), as recommended by focus group experts [5, 38].

Ipsative forced choice. Ipsative forced choice surveys, in which respondents choose a single preferred option from a fixed set of choices, have been studied and used in psychology [6], marketing research [15], and HCI user studies. Unlike these surveys, WYR does not require participants to use literacy skills, but WYR benefits from the ipsative forced choice structure in two key ways: (1) having only two choices helps reduce cognitive load and (2) offering contrasting choices helps children make comparisons, especially when the topics are abstract or complex. Cognitive load theory suggests that when children encounter a complex intellectual situation, they may require considerable cognitive effort. Therefore, in group dialogue, it is important to help children make sense and access their schemas in long-term memory, while helping them to reduce working memory load [53] by limiting to two choices.

In addition to reducing cognitive load, the choices presented in WYR provide intrinsic educational benefit and help children express feelings, values, reasons, or concerns about topics explicitly or implicitly in the WYR choices. Presenting contrasting cases to illustrate differentiation is a powerful educational tool [28] shown to help children "improve discernment" and understanding of a topic [51]. When engaging with WYR, children reason through their reaction to contrasting cases, articulating the distinctions, and the relevance of these distinctions, between the cases.

\subsection{Implications for Design}

In this paper we presented WYR as a method for children, but our pilot studies suggest that this technique may work well for many user groups. We encourage researchers and designers to help participants create their own WYR scenarios and try them out in other design contexts beyond work with children. Although the design prompts in many co-design techniques are generated by the researcher [60], WYR can be used as a way for participants themselves to produce prompts, and in doing so, reflect on their own values, models, beliefs, and opinions. By having participants create their own scenario, the researcher can also encourage shifts in power dynamics by helping the participants co-facilitate with designers the WYR that are on their minds [72]. Finally, designers and researchers can consider the kinds of ethical, moral, and ambiguous topics for which WYR could be suitable. Design is a series of decisions based on tradeoffs. While interviews, focus groups, and surveys may get to what individuals and groups want, these elicitation techniques may not make the tradeoffs clear. WYR makes such tradeoff and priorities salient and explicit. We encourage designers and researchers to consider scenarios and contexts for which tradeoffs in design are emphasized. 


\subsection{Limitations and Future Work}

We conducted this study in a single USA context in one urban area with children that are comfortable using technologies. Therefore, this study contributes more to theoretical generalizations, rather than statistical generalizations [68]. We also did not focus the study on design insights. Though we believe WYR is a powerful and broadly applicable method for delving into nuance and complexities with children (and others), it certainly has limitations. However, this is also a limitation in that as a group activity, WYR is at the whim of the participants. Because of the silly and fantastical nature of the scenarios, we noticed the KidsTeam UW children acting subversively (for better or for worse), sometimes trying to out-do each other with their reasons. To that effect, we encourage WYR, not as a definite choice over other options but as a way to elicit a spectrum of opinions, thoughts, and suggestions across a group of participants. WYR may not be suitable for some heavy topics for which it would be inappropriate to invoke silliness, or with certain groups or in certain settings. More generally, WYR may suffer from issues common to groups more generally: participants may decline to share certain preferences, context, or anecdotes, or may share a view that does not closely represent their true preference because someone else in the group shared it [56].

For future work we encourage researchers and designers to develop WYR in various settings, contexts, participant demographics, and styles. Researchers may consider varying the participant demographics, the number of participants, the settings (e.g., a public area, a classroom), and the voting mechanisms (e.g., voting with post-its, voting as an alternate perspective). Future work in WYR also lies in developing ways in which to distribute this technique wider, such as on an online digital platform that could reach other populations. We also need to consider how WYR can be altered to allow for participation for all, especially those in marginalized communities (e.g., neurodiversity) and accessibility issues (e.g., low vision, hearing impaired). By presenting WYR and having children create scenarios that makes tradeoffs a priority, we believe this technique can provide an authentic way for children and others to consider the issues that professional designers themselves must wrestle with.

\section{CONCLUSION}

Eliciting children's detailed perspectives on the technologies that affect their lives is a challenging but essential part of designing products that will serve them well. To support designers engaging in this difficult task, we developed WYR, a fanciful voting game inspired by the conversational game of the same name, that seeks to build intersubjectivity in groups of participants and scaffold participants in reasoning through nuanced tradeoffs. Overall, we conducted seven WYR sessions with 16 children over the course of a year. We found that in articulating their perspectives on these tradeoffs, participants were likely to surface contextual details about their lives, reveal details of their mental model of the technology under discussion, and elucidate their values. We see WYR as a useful tool for blending social play that can help children articulate their views with a design approach that is committed to creating child-centered artifacts.

\section{SELECTION AND PARTICIPATION OF CHILDREN}

Children who participated in our study were already engaged in KidsTeam UW. Recruitment for KidsTeam involved using flyers, mailing lists, and snowball sampling. The team is open to children ages 6-11. Parents gave written consent and children gave written assent prior to participation. We offered children breaks or alternative activities if they expressed that they did not want to participate at any point. Children are able to opt out of the research study at any time. All research has been approved by our institution's Institutional Review Board. Adult facilitators go through ethics and safety training for children at our institution. All sessions were video recorded, uploaded to secure and private institutional servers, and shared through password protected files.

\section{ACKNOWLEDGMENTS}

We are extremely grateful to all the students, staff, professors, and friends who helped us complete this project by supporting our pilot sessions and reading drafts of this paper, including Christine Chen, Christine Geeng, Melody Kadenko, Shrirang Mare, Alison Simko, Anna Kornfeld Simpson, Andrei Stabrovski, Karl Weintraub, and Eric Zeng. We are also very thankful to our anonymous reviewers for their constructive and positive critiques of this paper. We thank all the friends, families, and children that participated in this study.

This research was funded by the Jacobs Foundation, a gift from the CyLab Security and Privacy Institute at Carnegie Mellon University, the National Science Foundation's Graduate Research Fellowship Program, and the National Science Foundation through Grant CNS-1565252.

\section{REFERENCES}

[1] Peter Anderson. 2002. Assessment and development of executive function (EF) during childhood. Child neuropsychology 8, 2 (2002), 71-82.

[2] Richard C Anderson, Clark Chinn, Janice Chang, Martha Waggoner, and Hwajin Yi. 1997. On the logical integrity of children's arguments. Cognition and Instruction 15, 2 (1997), 135-167.

[3] James Auger. 2013. Speculative design: crafting the speculation. Digital Creativity 24, 1 (2013), 11-35.

[4] Liam J. Bannon and Pelle Ehn. 2012. Routledge international handbook of participatory design. Routledge.

[5] Rosaline Barbour. 2008. Doing focus groups. Sage.

[6] Helen Baron. 1996. Strengths and limitations of ipsative measurement. Fournal of Occupational and Organizational Psychology 69, 1 (1996), 49-56.

[7] Jared S. Bauer and Julie A. Kientz. 2013. DesignLibs: A Scenario-based Design Method for Ideation. In $\mathrm{CHI}$.

[8] Erling Björgvinsson, P. Ehn, and Per-Anders Hillgren. 2010. Participatory design and "democratizing innovation". In $P D C$ ' 10.

[9] Sue C Bratton, Dee Ray, Tammy Rhine, and Leslie Jones. 2005. The efficacy of play therapy with children: A meta-analytic review of treatment outcomes. Professional psychology: research and practice 36, 4 (2005), 376.

[10] John C Brigham, Mary Van Verst, and Robert K Bothwell. 1986. Accuracy of children's eyewitness identifications in a field setting. Basic and Applied Social Psychology 7, 4 (1986), 295-306.

[11] Kathy Charmaz. 2006. Constructing grounded theory: A practical guide through qualitative analysis. sage.

[12] Nathan H Clemens, Kelsey Ragan, and Oscar Widales-Benitez. 2016. Reading difficulties in young children: beyond basic early literacy skills. Policy Insights from the Behavioral and Brain Sciences 3, 2 (2016), 177-184.

[13] Paul Coulton, Dan Burnett, and Adrian Ioan Gradinar. 2016. Games as speculative design: allowing players to consider alternate presents and plausible futures. (2016).

[14] John W Creswell, William E Hanson, Vicki L Clark Plano, and Alejandro Morales. 2007. Qualitative research designs: Selection and implementation. The counseling psychologist 35, 2 (2007), 236-264. 
[15] Ravi Dhar and Itamar Simonson. 2003. The effect of forced choice on choice Journal of marketing research 40, 2 (2003), 146-160.

[16] Christian Dindler, Eva Eriksson, Ole Sejer Iversen, Andreas Lykke-Olesen, and Martin Ludvigsen. 2005. Mission from Mars: a method for exploring user requirements for children in a narrative space. In Proceedings of the 2005 conference on Interaction design and children. 40-47.

[17] Christian Dindler and Ole Sejer Iversen. 2007. Fictional Inquiry-design collaboration in a shared narrative space. CoDesign 3, 4 (2007), 213-234.

[18] B. DiSalvo, Jason C. Yip, Elizabeth Bonsignore, and C. DiSalvo. 2017. Participatory Design for Learning : Perspectives from Practice and Research.

[19] Allison Druin. 1999. Cooperative inquiry: developing new technologies for children with children. In Proceedings of the SIGCHI conference on Human Factors in Computing Systems. 592-599.

[20] Allison Druin. 2002. The role of children in the design of new technology. Behaviour and information technology 21, 1 (2002), 1-25.

[21] Allison Druin. 2005. What children can teach us: Developing digital libraries for children with children. The library quarterly 75, 1 (2005), 20-41.

[22] Pelle Ehn. 1992. Scandinavian design: On participation and skill

[23] Pelle Ehn. 2008. Participation in design things. In Proceedings Participatory Design Conference 2008. ACM.

[24] Either [n.d.]. Either - A game of preference. either.io/. Accessed: 2019-09-14.

[25] C. Frauenberger, Julia Makhaeva, and K. Spiel. 2017. Blending Methods: Developing Participatory Design Sessions for Autistic Children. Proceedings of the 2017 Conference on Interaction Design and Children (2017).

[26] James H Frey and Andrea Fontana. 1991. The group interview in social research. The Social Science fournal 28, 2 (1991), 175-187.

[27] Jennifer E Gibson. 2012. Interviews and focus groups with children: Methods that match children's developing competencies. Journal of Family Theory \& Review 4 2 (2012), 148-159.

[28] James J Gibson and Eleanor J Gibson. 1955. Perceptual learning: Differentiation or enrichment? Psychological review 62, 1 (1955), 32.

[29] Mona Leigh Guha, Allison Druin, Gene Chipman, Jerry Alan Fails, Sante Simms, and Allison Farber. 2004. Mixing ideas: a new technique for working with young children as design partners. In Proceedings of the 2004 conference on Interaction design and children: building a community. 35-42.

[30] Mona Leigh Guha, Allison Druin, and Jerry Alan Fails. 2013. Cooperative Inquiry revisited: Reflections of the past and guidelines for the future of intergenerational co-design. International fournal of Child-Computer Interaction 1, 1 (2013), 14-23.

[31] Joachim Halse, Eva Brandt, Brendon Clark, and Thomas Binder. 2010. Rehearsing the future. The Danish Design School Press.

[32] David Hammer and Leema K Berland. 2014. Confusing claims for data: A critique of common practices for presenting qualitative research on learning. Fournal of the Learning Sciences 23, 1 (2014), 37-46.

[33] Jennifer Hammond and Pauline Gibbons. 2005. What is scaffolding. Teachers voices 8 (2005), 8-16.

[34] R Hansen and J Grossmen. 2008. Clickjacking. http://www.sectheory.com/ clickjacking.htm.

[35] Lin-Shung Huang, Alex Moshchuk, Helen J Wang, Stuart Schecter, and Collin Jackson. 2012. Clickjacking: Attacks and defenses. In 21st \{USENIX\} Security Symposium ( $\{$ USENIX $\}$ Security 12). 413-428.

[36] Ole Iversen, R. C. Smith, and Christian Dindler. 2017. Child as Protagonist: Expanding the Role of Children in Participatory Design. Proceedings of the 2017 Conference on Interaction Design and Children (2017).

[37] Jackbox Games [n.d.]. Split The Room - Jackbox Games. jackboxgames.com/splitthe-room/. Accessed: 2019-09-14.

[38] Richard A Krueger. 1994. Focus groups : A practical guide for applied research.

[39] Priya Kumar, Shalmali Milind Naik, Utkarsha Ramesh Devkar, Marshini Chetty, Tamara L. Clegg, and Jessica Vitak. 2017. 'No Telling Passcodes Out Because They're Private': Understanding Children's Mental Models of Privacy and Security Online. Proc. ACM Hum.-Comput. Interact. 1, CSCW, Article 64 (Dec. 2017), 21 pages. https://doi.org/10.1145/3134699

[40] Nora McDonald, Sarita Schoenebeck, and Andrea Forte. 2019. Reliability and inter-rater reliability in qualitative research: Norms and guidelines for CSCW and HCI practice. Proceedings of the ACM on Human-Computer Interaction 3, CSCW (2019), 1-23.

[41] Alessandra Melonio and Rosella Gennari. 2012. Co-Design with children: the State of the Art. Italy: KRBD Research Centre for Knowledge and Data. University of Bozen (2012).

[42] Neil Mercer and Karen Littleton. 2007. Dialogue and the development of children's thinking: A sociocultural approach. Routledge.

[43] Neema Moraveji, Jason Li, Jiarong Ding, Patrick O'Kelley, and Suze Woolf. 2007. Comicboarding: using comics as proxies for participatory design with children. In Proceedings of the SIGCHI conference on Human factors in computing systems. 1371-1374.

[44] David L. Morgan. 1996. Focus Groups. Annual Review of Sociology 22 (1996), 129-152. http://www.jstor.org/stable/2083427

[45] Barbara Murphy, Jill Cockburn, and Michael Murphy. 1992. Focus groups in health research. Health Promotion fournal of Australia 2, 2 (1992), 37-40.
[46] Remee Patel. 2017. This "Would You Rather" Test Will Reveal If You're Addicted To Your Phone. www.buzzfeed.com/remeepatel/this-game-of-would-you-ratherwill-reveal-if-youre-addicted.

[47] Jean Piaget. 2013. Play, dreams and imitation in childhood. Vol. 25. Routledge.

[48] Janet C Read, Peggy Gregory, Stuart MacFarlane, Barbara McManus, Peter Gray, and Raj Patel. 2002. An investigation of participatory design with childreninformant, balanced and facilitated design. In Interaction design and Children. Eindhoven, 53-64.

[49] Victoria Rideout and Michael B. Robb. 2020. The Common Sense Census: Media Use by Kids Age Zero to Eight. https://www.commonsensemedia.org/sites/ default/files/uploads/research/2020 zero to eight_census_final_web.pdf.

[50] Claudia M Roebers and Wolfgang Schneider. 2000. The impact of misleading questions on eyewitness memory in children and adults. Applied Cognitive Psychology: The Official fournal of the Society for Applied Research in Memory and Cognition 14, 6 (2000), 509-526.

[51] Daniel L Schwartz, Catherine C Chase, Marily A Oppezzo, and Doris B Chin. 2011. Practicing versus inventing with contrasting cases: The effects of telling first on learning and transfer. Fournal of Educational Psychology 103, 4 (2011), 759.

[52] Katta Spiel, E. Brulé, C. Frauenberger, G. Bailly, and G. Fitzpatrick. 2018. Microethics for participatory design with marginalised children. Proceedings of the 15th Participatory Design Conference: Full Papers - Volume 1 (2018)

[53] John Sweller. 1994. Cognitive load theory, learning difficulty, and instructional design. Learning and instruction 4, 4 (1994), 295-312.

[54] Olaf Tans. 2006. The fluidity of warrants: Using the Toulmin model to analyse practical discourse. In Arguing on the Toulmin Model. Springer, 219-230.

[55] Adriana J Umaña-Taylor and Mayra Y Bámaca. 2004. Conducting focus groups with Latino populations: Lessons from the field. Family Relations 53, 3 (2004), 261-272.

[56] Maarten Van Mechelen, Mathieu Gielen, Vero Vanden Abeele, Ann Laenen, and Bieke Zaman. 2014. Exploring challenging group dynamics in participatory design with children. In Proceedings of the 2014 conference on Interaction design and children. 269-272.

[57] Maarten Van Mechelen, Bieke Zaman, Ann Laenen, and Vero Vanden Abeele. 2015. Challenging group dynamics in participatory design with children: lessons from social interdependence theory. In Proceedings of the 14th International Conference on Interaction Design and Children. 219-228.

[58] Bert Van Oers. 2012. Meaningful cultural learning by imitative participation: The case of abstract thinking in primary school. Human Development 55, 3 (2012), $136-158$

[59] Lev Semenovich Vygotsky. 1980. Mind in society: The development of higher psychological processes. Harvard university press.

[60] Greg Walsh, Elizabeth Foss, Jason Yip, and Allison Druin. 2013. FACIT PD: a framework for analysis and creation of intergenerational techniques for participatory design. In proceedings of the SIGCHI Conference on Human Factors in Computing Systems. 2893-2902.

[61] Greg Walsh, Elizabeth Foss, Jason Yip, and Allison Druin. 2013. Octoract: an eightdimensional framework for intergenerational participatory design techniques. In Proceedings of the SIGCHI Conference on Human Factors in Computing Systems-CHI, Vol. 13.

[62] J. Wertsch. 1985. Vygotsky and the Social Formation of Mind.

[63] Helen L Westcott and Karen S Littleton. 2005. Exploring meaning in interviews. Researching children's experience: Methods and approaches (2005), 141-179.

[64] Victoria Whitington and Irene Floyd. 2009. Creating intersubjectivity during socio-dramatic play at an Australian kindergarten. Early Child Development and Care 179 (2009), 143 - 156

[65] Wikipedia [n.d.]. Would you rather-Wikipedia. en.wikipedia.org/wiki/Would you rather. Accessed: 2019-06-08.

[66] David Wood, Jerome S Bruner, and Gail Ross. 1976. The role of tutoring in problem solving. Fournal of child psychology and psychiatry 17, 2 (1976), 89-100.

[67] Julia Woodward, Zari McFadden, Nicole Shiver, Amir Ben-hayon, Jason C Yip, and Lisa Anthony. 2018. Using co-design to examine how children conceptualize intelligent interfaces. In Proceedings of the 2018 CHI Conference on Human Factors in Computing Systems. 1-14.

[68] Robert K Yin. 2017. Case study research and applications: Design and methods. Sage publications.

[69] Jason C. Yip, Tamara L. Clegg, Elizabeth M. Bonsignore, H. Gelderblom, Emily Rhodes, and A. Druin. 2013. Brownies or bags-of-stuff?: domain expertise in cooperative inquiry with children. Proceedings of the 12th International Conference on Interaction Design and Children (2013)

[70] Jason C Yip, Kung Jin Lee, and Jin Ha Lee. 2020. Design partnerships for participatory librarianship: A conceptual model for understanding librarians co designing with digital youth. Fournal of the Association for Information Science and Technology 71, 10 (2020), 1242-1256.

[71] Jason C Yip, Kiley Sobel, Xin Gao, Allison Marie Hishikawa, Alexis Lim, Laura Meng, Romaine Flor Ofiana, Justin Park, and Alexis Hiniker. 2019. Laughing is Scary, but Farting is Cute: A Conceptual Model of Children's Perspectives of Creepy Technologies. In Proceedings of the 2019 CHI Conference on Human Factors 
in Computing Systems. 1-15.

[72] Jason C Yip, Kiley Sobel, Caroline Pitt, Kung Jin Lee, Sijin Chen, Kari Nasu, and Laura R Pina. 2017. Examining adult-child interactions in intergenerational participatory design. In Proceedings of the 2017 CHI Conference on Human Factors in Computing Systems. 5742-5754.

[73] Philip David Zelazo, Ulrich Müller, Douglas Frye, and Stuart Marcovitch. 2003 The development of executive function in early childhood: I. The development of executive function. Monographs of the society for research in child development (2003).

[74] J. Zlatev. 2013. The mimesis hierarchy of semiotic development: five stages of intersubjectivity in children.

\section{A DESCRIPTIONS OF PILOT SESSIONS}

As described in Section 3.4, we conducted seven pilot sessions to develop the WYR methodology. Table 3 conveys more details about each of these pilot sessions.

\section{B WYR SCENARIO TEMPLATES}

We have found that knowledge of common structures of WYR scenarios is useful for researchers generating scenarios or guiding participants toward better scenarios. The following list of WYR scenario structures and concrete examples is a useful starting point but is not intended to be exhaustive.

- Always or Never. WYR Always appear as "online" or never appear as "online"?

- Extreme Opposites. WYR your smart thermostat malfunctions and sets the temperature in your home to-10 degrees in the winter or 100 degrees in the summer?

- Varying the stakeholder. WYR your parents see all of the photos on your phone or your colleagues and boss see all the photos on your phone?

- Data Loss or Data Compromise. WYR your parents see all the photos on your phone or all of the photos on your phone are deleted forever?

- Varying the asset (e.g., type of data) that is impacted. WYR your parents see all the photos on your phone or all of your Internet browsing and search history?

- Altering the likelihood, frequency, or length of impact. WYR 100 days without Internet or 100 days when anyone can read your mind? WYR have to re-type your password every time you look at your phone or have to authenticate with a finger prick of blood once per day every day? WYR your partner sees a really mean breakup text you sent but no longer mean or risk the possibility of getting caught sneaking into their phone to delete it?

- A but B or A' but B'. WYR find the love of your life tomorrow but also have a stalker or take 10 years to find the love of your life but everyone you meet in the meantime is kind to you?

\section{ALL WYR SCENARIOS FROM THE SEVEN SESSIONS WITH CHILDREN}

For completeness, we document here all scenarios that the children formally voted on throughout the seven design sessions (WYR1-7). WYR1 scenarios, pre-generated by researchers theme (creepy technology):

- WYR play with a cute robot that secretly changes your Wi-Fi password OR play with a scary robot that does not secretly change anything?
- WYR play with the cute robot that tries to subtly play tricks on you OR play with the scary robot that's honest about you?

- WYR use an Alexa device that records everything you say, or use an Alexa device that pretends it's your parent?

- WYR play with a cute robot but you can't control when it laughs randomly OR play with a cute robot, but you can't control when it controls your voice?

- WYR play with a cute robot that constantly monitors how much you exercise OR use an Alexa device where you control everything it does?

- WYR play with a cute robot that constantly sends information to your parents OR play with a scary robot that sends some information to your parents?

- WYR use a smartphone for as much as you want but it secretly tries to get you to buy stuff OR use a smartphone for one hour a day, and it is honest to you about money?

- WYR play with a robot that secretly sends information about you to a company OR play with a robot that beeps constantly when it sends your information to a company?

- WYR use the iPhone but Siri automatically shuts down videos and fun games OR use the iPhone, but Siri tries to act like your parent?

- WYR use Alexa but you can't control the skills that are being used OR use Alexa but it randomly laughs in awkward moments?

WYR2 scenarios, participant-generated starting from a single example, with researcher guidance (theme: creepy technology):

- (Example) WYR Wear a device that can tell everyone your thoughts for 5 minutes OR not play with a phone for an entire year?

- WYR use a website that gives you good gift suggestions but tells the person you're giving the gift what the gift is OR use a website that gives you bad gift suggestions but does not tell the person you are giving the gift to, it keeps the secret right?

- WYR play a game you like with lots of ads pop up randomly OR play a game you don't like but control number of ads?

- WYR play with scary looking with bloody sharp teeth but nice robot OR play with a cute robot that might lie to you?

- WYR play with a tutor robot that acts like your parent and tells you when to do your HW OR waiter robot that switches your food that you might be allergic to?

- WYR play with a creepy robot that acts like your parent and watches you during the night or robot with a creepy smile that randomly play scary clown music?

- WYR have a phone that records you and tries to make you sad OR mimics you and try to send messages to your friend as you?

WYR3 scenarios, pre-generated by researchers (theme: creepy technology):

- WYR have a phone that punches you every hour or gives you $\$ 100$ million dollars but brings robbers to your house?

- Have a phone that prevents you from having fun or phone that secretly watches you? 
- WYR play with a robot that laughs at all your jokes OR play with a robot that laughs randomly at night?

- WYR own a smartphone and do whatever you want but limited time (small, 10,000 mins) or own a smartphone forever but only text and call?

- WYR play with a robot that gives you food and water when you need it or a robot that cuddles you at night?

- WYR play with a robot that acts like you and steals your identity or plays with a robot that looks scary?

- WYR play with a robot that secretly watches you at night OR play with a robot that secretly sends information about you to your parents?

- WYR play with a robot that secretly watches you at night and makes a strange buzzing noise or play with a robot that secretly sends information about the games you download and sends every bit of info to your parents?

- WYR have to retype your password every time you use your phone, but it resets every time doesn't store information or have to get a sharp poke every time and your phone slowly breaks down every time?

WYR4 scenarios, pre-generated by researchers (theme: school):

- When you've finished your homework, WYR your teacher explains a problem to you after they've graded it OR be able to immediately check only if your answers are right or wrong, but not know why?

- WYR your teacher knows exactly how long you spent on homework (which means they can adjust to be sure they're assigning the right amount of work) OR you have 5 hours of homework every day and the teacher has no idea how long you're spending?

- WYR your teacher know exactly when you are doing your homework OR you get all of your homework assignments for the whole year and can do them whenever and turn them in at the end of the year?

- WYR your parents can always check when you're doing homework (in an app) OR you can't ask your parents for help with homework?

- WYR your parents are able to communicate with your teacher whenever they want through the app (e.g., signing permission slips you forgot, praising your good work, but also able to discuss bad test grades) OR your parents can't ever talk to your teacher (even on your behalf, to help you)

WYR5 scenarios, participant-generated with researcher guidance and pre-generated example scenarios to tweak (theme: YouTube):

- WYR watch your favorite YouTuber (kids: PewDiePie) or your best friend (kids: Lucas)

- WYR every time you click on or watch a video, it erases it from your account OR watch boring videos that you cannot choose or skip?

- (adjusted during voting) WYR have limited horrible videos or one good video per day?

- WYR have no YouTube but Netflix OR YouTube but no Netflix?

WYR6 scenarios, pregenerated, conducted viz Zoom due to Covid19 (theme: positive scenarios):
- WYR spend a day in an unbelievably fun virtual reality world OR spend a day at a local amusement park?

- WYR have unlimited favorite snacks OR have unlimited access to all favorite video games?

- WYR have candy that does not cause cavities OR have candy that can improve your gaming skills?

- WYR never have to go back to school OR never have to go back on Zoom?

- WYR cook together with your family OR use a smartphone to order food with your family?

WYR7 scenarios, participant-generated with researcher guidance and pre-session use of the game, conducted via Zoom due to Covid19 (theme: slither.io):

- WYR play with only your friends OR play with lots of strangers?

- WYR have infinite zoom so you don't poop out little worm bits and get smaller when you zoom OR grow by two times the normal amount when you eat things?

- WYR play with your friends OR you control one worm with your friends?

\section{PRACTICAL GUIDANCE SUMMARY FOR PRACTITIONERS}

Figure 3 was included to summarize the key points from Section 3, as a quick reference for practitioners using the method.

\section{E CODEBOOK}

Table 4 shows the codebook that we generated based on the seven WYR sessions we ran with children. 


\begin{tabular}{|c|c|c|c|c|c|c|c|}
\hline 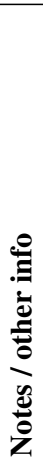 & 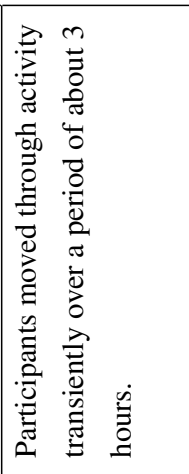 & 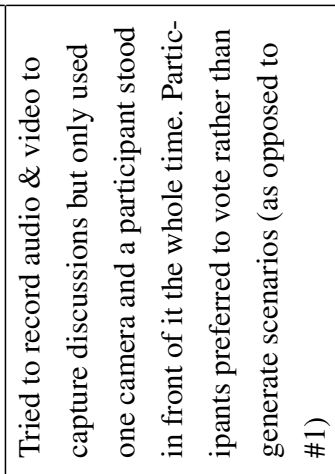 & 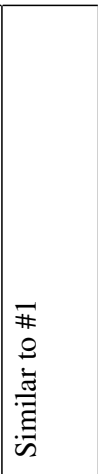 & 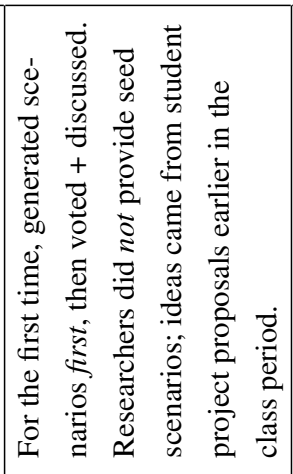 & 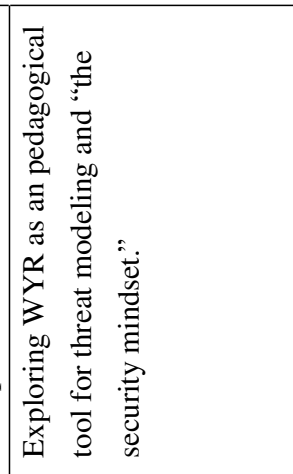 & 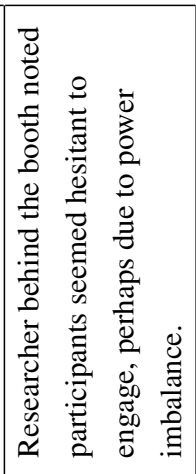 & \\
\hline & 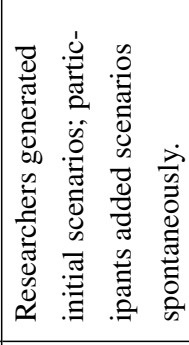 & $\therefore$ & $=$ & 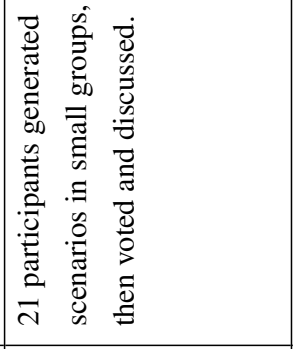 & 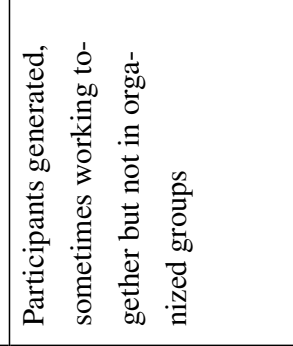 & 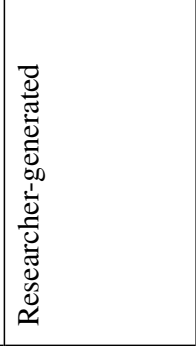 & 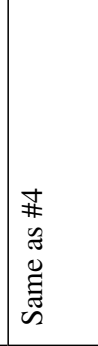 \\
\hline 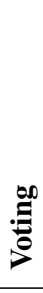 & 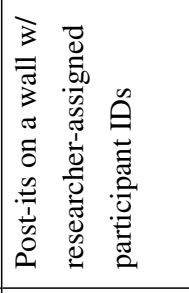 & $\therefore$ & $\therefore$ & 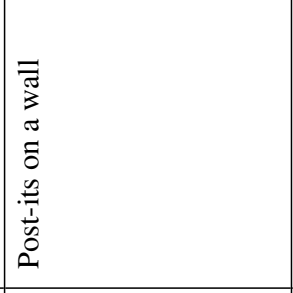 & 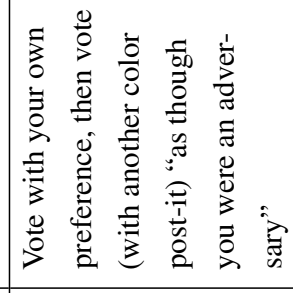 & 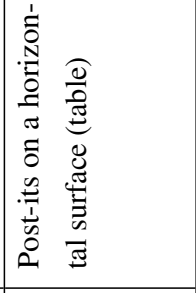 & $\therefore$ \\
\hline 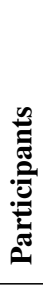 & 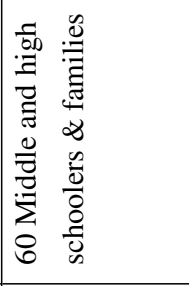 & 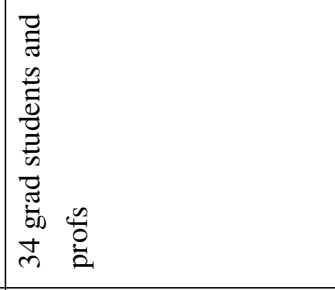 & 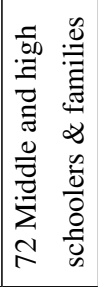 & 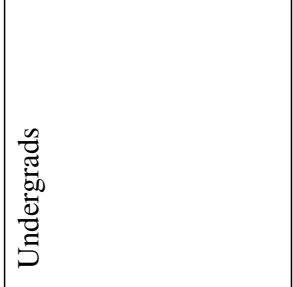 & 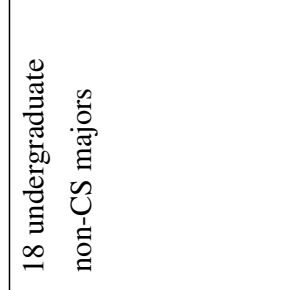 & 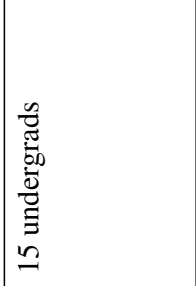 & 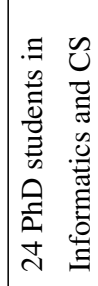 \\
\hline 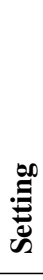 & 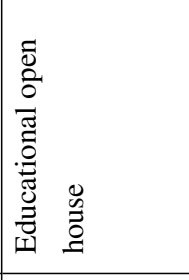 & 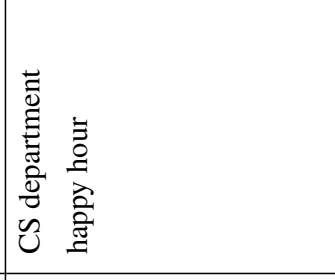 & 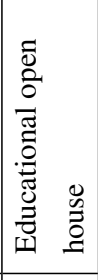 & 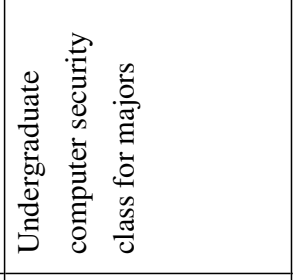 & 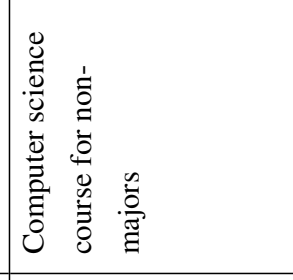 & 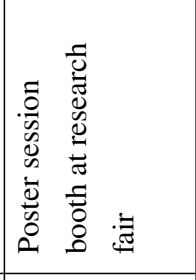 & 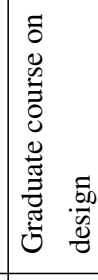 \\
\hline 袌 & 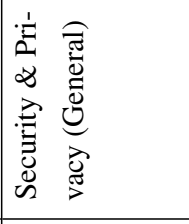 & $\therefore$ & $\therefore$ & $\therefore$ & : & 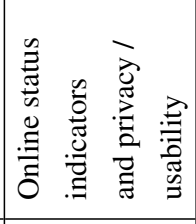 & 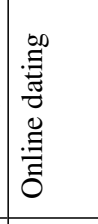 \\
\hline$\frac{\vec{\theta}}{\vec{\theta}}$ & - & $\sim$ & $m$ & 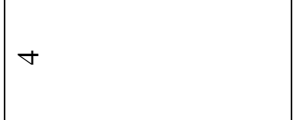 & n & 0 & 1 \\
\hline
\end{tabular}

Table 3: Description of the topic, setting, participants, voting mechanisms, how scenarios were generated, and other relevant aspects of the seven pilot sessions used to develop WYR. 


\section{Practical guidance for using \\ "Would You Rather: A Focus Group Methodology"}

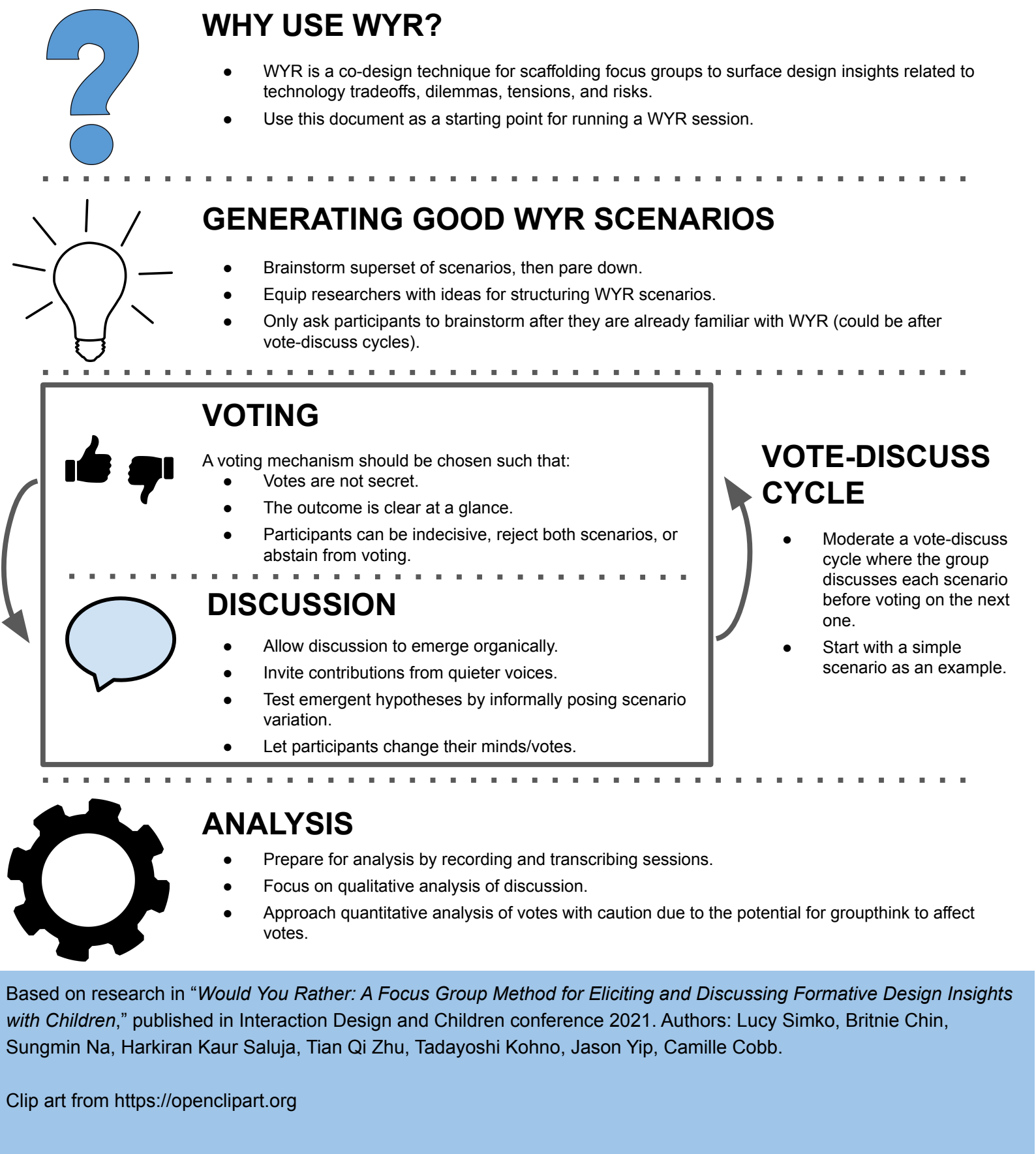

Figure 3: This graphic conveys practical guidance for practitioners using WYR. 


\begin{tabular}{|c|c|c|}
\hline Code & Description & Example \\
\hline \multirow[t]{3}{*}{ Situation Type } & $\begin{array}{l}\text { Unreal situations that are very fan- } \\
\text { ciful and extreme. }\end{array}$ & $\begin{array}{l}\text { "if you bring homework first in three months, you get a prize, one million } \\
\text { dollar gift card prize." }\end{array}$ \\
\hline & $\begin{array}{l}\text { Pragmatic situations that appear } \\
\text { real and could happen. }\end{array}$ & $\begin{array}{l}\text { "Our question was would you rather have your parents annoy you while } \\
\text { you do your homework or have to do twice as much homework." }\end{array}$ \\
\hline & $\begin{array}{l}\text { Hybrid situation are a mix of the } \\
\text { pragmatic and unreal situations that } \\
\text { are linked together. }\end{array}$ & $\begin{array}{l}\text { "There is tiny camera on the HW itself, if you don't do your HW fast } \\
\text { enough, will have twice as much HW and twice little time; camera is } \\
\text { attached to devices; there are symbols displayed for teacher about the } \\
\text { students' completion time (ie. five dots, five lines); there's a teacher } \\
\text { who is sitting in front of the computer screen, then they can monitor } \\
\text { what is happening through the security camera; can see what students } \\
\text { are doing through computer screen." }\end{array}$ \\
\hline Debate & $\begin{array}{l}\text { Situations in which two or more } \\
\text { children debate, argue, and elabo- } \\
\text { rate the WYR. }\end{array}$ & $\begin{array}{l}\text { Researcher: "Ohh so you're saying it can watch you, but it's not gonna } \\
\text { be telling anyone. It's just watching it records does it say it's going to } \\
\text { tell anyone okay so that's an interesting choice" } \\
\text { Jade: "But it'll watch you in the bathroom" } \\
\text { Researcher: "But maybe it watches you in the bathroom. But you have } \\
\text { to know it watches you in the bathroom." } \\
\text { Henry: "That's only if you bring it into the bathroom" }\end{array}$ \\
\hline \multirow[t]{2}{*}{ Uniform vs. Split } & $\begin{array}{l}\text { Split: Children create situations that } \\
\text { have complexity and create tension } \\
\text { for the group. }\end{array}$ & $\begin{array}{l}\text { Have a phone that punches you every hour or gives you } \$ 100 \text { million } \\
\text { dollars but brings robbers to your house (group splits in their response) }\end{array}$ \\
\hline & $\begin{array}{l}\text { Uniform: Children create situations } \\
\text { that have a pretty uniform response } \\
\text { from the group. }\end{array}$ & $\begin{array}{l}\text { Would you rather play with a robot that annoyingly laughs at all your } \\
\text { jokes or play with a robot that has a creepy or evil laugh at night? } \\
\text { (uniform response to the second situation) }\end{array}$ \\
\hline Clarity and process & $\begin{array}{l}\text { Did the children ask for help or } \\
\text { more elaboration on the WYR sit- } \\
\text { uation? }\end{array}$ & $\begin{array}{l}\text { Adult: "Honest robot, scary honest robot versus cute deceptive robot. } \\
\text { Deceptive like plays a trick. It's secretly plays tricks on you. Not bad } \\
\text { tricks, they just does, right. Versus-" } \\
\text { Fiona: "Like whoopee cushion?" }\end{array}$ \\
\hline Contextual detail & $\begin{array}{l}\text { We learn more about the children's } \\
\text { lives in their WYR response. }\end{array}$ & Child: Anyways, my parents don't really check their emails. \\
\hline Coping strategies & $\begin{array}{l}\text { We learn how they take control } \\
\text { of the WYR situation (e.g., making } \\
\text { loopholes, being arrogant, turn tech- } \\
\text { nology on/off). }\end{array}$ & $\begin{array}{l}\text { Henry: "The thing about the creepy robot that acts, that acts like your } \\
\text { parent and watches at night, you could punch it!" } \\
\text { Dwight: "You could kill it, destroy it!" }\end{array}$ \\
\hline Mental models & $\begin{array}{l}\text { We learn how they think about how } \\
\text { technology works. }\end{array}$ & $\begin{array}{l}\text { Adult: "Okay, so I can choose to ignore it. Why did no one pick number } \\
\text { one? Like-the Alexa device that records everything you say?" } \\
\text { Pat: "It can sell your information!" Fiona: "It can sell it!" }\end{array}$ \\
\hline Values & $\begin{array}{l}\text { We learn about what they value or } \\
\text { what they think others value. }\end{array}$ & $\begin{array}{l}\text { Mike: "Wifi is my life." Norm: "Because it's (scary toy) nice, like you } \\
\text { want to be with someone who is nice, who cares if it is bloody." }\end{array}$ \\
\hline Tensions & $\begin{array}{l}\text { We learn about what they see as a } \\
\text { tension or opposition }\end{array}$ & $\begin{array}{l}\text { Pat: "Just think about new fun games. Just get new fun games. " Adult: } \\
\text { "Oh okay, okay, okay. So, it has to know that [?]" Ash: "What if it (the } \\
\text { game) wasn't fun, but you really want it?" Fiona: "If it had a zero-star } \\
\text { rating and you loved it so much." }\end{array}$ \\
\hline Power dynamics & $\begin{array}{l}\text { We learn what children consider as } \\
\text { authorities in their life. }\end{array}$ & $\begin{array}{l}\text { Dwight: "And [?] you have to check it five times, and every time it has } \\
\text { to be right. And the teacher knows everything is right because there's } \\
\text { a security camera." }\end{array}$ \\
\hline
\end{tabular}

Table 4: Codebook for WYR sessions with children, which includes ten codes, their descriptions, and examples of each. 